\title{
Innovative Practice Deserves Significantly Less Restrictive Policy
}

\author{
Voultsos P* \\ Assstant Professor of Medical Ethics, Aristotle University of Thessaloniki (School of Medicine), Greece
}

Submission: March 11, 2019; Published: March 20, 2019

*Corresponding author: Voultsos P, Assstant Professor of Medical Ethics, Aristotle University of Thessaloniki (School of Medicine), Greece

\section{Mini Review}

Innovative practice is the use of innovative interventions, namely, interventions that deviate from standard or accepted clinical practice to enhance the well-being of individual patients in the course of their care. Innovative practice subjects some people to the risk of harm in order to benefit them, provided that there is a reasonable expectation of that outcome, with the foreseeable possibility that others could subsequently be harmed or benefited. Clinical research subjects some people to the risk of harm in order to benefit other people. J. Earl arguably writes that innovative practice raises two categories of serious concerns: those focused on the patient to whom it is administered and those focused on population due to widespread adoption of harmful or non-beneficial intervention among clinicians ('runaway diffusion') [1]. Importantly, the ethical worries about 'runaway diffusion' are empirically undetermined [1]. The author puts it best in saying that engaging in innovative practice deviates from both idealized expert-consensus standard and research standards (dual deviation approach). He suggests that these deviations should be justified in a proscriptive oversight approach involving prospective dual deviation review. In this perspective, the author specifies (though not fully) some guidelines that could mitigate reviewers' idiosyncratic judgments to wholly determine whether clinicians have adequately justified deviating from research standards [1]. However, such a positive control (review) leaves the door open for such judgments, which may unjustifiably burden on the health/well-being of the patient and the moral well-being of the clinician, especially in the context of beneficence-centered bioethics and patient-centered health care. I go into.

The prospective dual review approach advanced in the manuscript is a moderately restrictive (precautionary) position, which however, should not be regarded as one-size-fits-all policy for overseeing innovative practice, aiming at mitigating the risk of runaway diffusion. I am sure it is right that the guidelines specified by J. Earl prevent the reviewers' idiosyncratic judgments from wholly determining whether clinicians have adequately justified deviating from research standards. Nevertheless, under particular circumstances, the reviewers' idiosyncratic judgments should wholly or partly not determine whether clinicians have adequately justified deviating from research standards. In a type of maximalist bioethics that is beneficence-centered, the needs of a particular patient may provoke clinician's moral responsibility. However, the reviewers' biomedical or ethical model may be illsuited to the conditions and needs of that particular patient in both practical and philosophical terms. For instance, in case that

a) the patient is at 'high risk of serious harm' and there is no other equivalent and viable alternative treatment (see the presented in the Earl's manuscript case of patient Hobbs dying of severe sepsis [1])

b) the patient autonomously has chosen to undergo innovative intervention

c) and there is reasonable expectation for positive outcome with regard to the particular patient

The prospective dual review may unjustifiably burden not only on the autonomy of both clinician and patient, but also on patient's health/well-being and clinician's moral well-being. If the aforementioned requirements are met, less restrictive policies concerning the innovative practice ought to be preferable to policies that are more restrictive. A less restrictive (if not excessively permissive) position would better respond to the enhanced principle of beneficence in the context of beneficence-centered bioethics. In the context of a type of health care that is patient-centered and a type of bioethics that places considerable emphasis on values such as vulnerability, solidarity and beneficence, the clinician's duty to provide what she has good reasons to regard as the best option for her patient (namely, her enhanced duty of beneficence) ought to be considered that outweighs the clinician's duty to mitigate the risk of runaway diffusion (namely, her duty of nonmaleficence) provided that the worries about the risks related to runaway diffusion are empirically undetermined.

J Earl writes 'since our current best is not enough we are ethically required to innovate in medicine.' In the context of 
beneficence-centered bioethics it would translate into the following statement: 'since our current best is not enough we are ethically required to innovate and further ease the innovative practice policy stance in medicine.' Rethinking of the principle of beneficence in the context of modern bioethics is increasingly recognized due to the fact that a wide-ranging account of the role of the values solidarity and vulnerability gains ground. The bioethics of the future should not be minimalist bioethics. It should be maximalist bioethics. In the prospective of the rapid progresses in biotechnology, bioethics should shift the focus from the principles of autonomy and nonmaleficence towards the principles of justice and beneficence, namely, a never satisfied principle that is strictly associated with the concept vulnerability, which may be conceptualized not only in the broad sense of the term, but also in an over-inclusive way, provided that humans are vulnerable beings by their own nature (humanity) [2].

It is to be highlighted that even in traditional medicine the principle of beneficence may be thought of as carrying great specific weigh. Pellegrino and Thomasma put it best in writing that 'medical good is only one of the components of the complex notion of patient good. The key concept is beneficence in trust' [3]. Consider the altruistic aspects of care in terms of Levinas' ethics, which anchors moral imperative of responsibility in human vulnerability $[4,5]$. The suffering of patient ('other' in levinasean ethics) provokes moral responsibility [4,5]. Suffering of vulnerable humans provokes responsibility for treating that responds to the imperative of beneficence $[4,5]$. Note, besides, that the clinician's response to this imperative (namely, the clinician's moral responsibility) may be enhanced by empathyrelated distress. Importantly, "intuitive medical response" of most physicians is to abide by the moral duty to fulfill their primary obligation to provide care to the patient who needs it [6]. In light of these considerations, under particular circumstances the clinician's disposal to benefit may be converted to moral obligation to benefit.

\section{Conclusion}

While in principle clinicians should not engage in innovative practice without prior approval, this consideration is not always ethically better. In some cases (in my opinion, in the vast majority of the instances of innovative practice) the prior positive approval can (or should) be waived or set aside in a specific way: engaging in innovative practice ought to be subjected to negative control of misuse of clinicians' discretionary authority in medical decisionmaking. Under particular circumstances, the discretionary space of professional (medical) practice deserves a broad measure of tolerance, especially in the context of beneficence-centered clinical ethics.

\section{References}

1. Earl J (2019) Innovative Practice, Clinical Research, and the Ethical Advancement of Medicine. Am J Bioeth.

2. Rogers W, Mackenzie C, Dodds S (2012) Why Bioethics needs a concept of vulnerability. International Journal of Feminist Approaches to Bioethics 5(2): 11-32.

3. Pellegrino ED, Thomasma DC (1993) The Virtues in Medical Practice. Oxford University Press, New York, USA, p. 73-74.

4. Burns L (2017) What Does the Patient Say? Levinas and Medical Ethics. J Med Philos 42(2): 214-235.

5. Svandra P (2018) An introduction to the thought of Emmanuel Levinas. The care or irreducible worry of infinite responsibility. Rech Soins Infirm 132: 91-98.

6. Sommerville A (2003) Juggling law, ethics, and intuition: practical answers to awkward questions. J Med Ethics 29(5): 281-286.

\section{Your next submission with Juniper Publishers will reach you the below assets}

- Quality Editorial service

- Swift Peer Review

- Reprints availability

- E-prints Service

- Manuscript Podcast for convenient understanding

- Global attainment for your research

- Manuscript accessibility in different formats

( Pdf, E-pub, Full Text, Audio)

- Unceasing customer service

Track the below URL for one-step submission

https://juniperpublishers.com/online-submission.php 